\title{
THE HEEL PAD IN PLANTAR HEEL PAIN
}

\author{
SOMCHAI PRICHASUK
}

From Ramathibodi Hospital, Bangkok, Thailand

A study of heel-pad thickness and compressibility using lateral radiographs, loaded and unloaded by body-weight, was carried out on 70 patients with plantar heel pain and 200 normal subjects. The heel-pad thickness and the compressibility index (resistance to compression) were greater in the patients than in normal subjects and significantly increased with age. In normal subjects, the thickness was greater in males than in females, but there was no significant difference in the compressibility. Increased weight led to an increase in heel-pad thickness and compressibility index. The body mass index was greater in patients with plantar heel pain than in normal subjects and $40 \%$ of the patients were considered to be overweight. Increase in the compressibility index indicates loss of elasticity and an increased tendency to develop plantar heel pain.

J Bone Joint Surg [Br] 1994; 76-B:140-2.

Received 18 November 1992; Accepted after revision 17 June 1993

Plantar heel pain, or 'plantar fasciitis', is a clinical syndrome characterised by pain and tenderness beneath the heel which are typically worse in the morning and improve after the first few steps of the day. The aetiology, pathology and treatment are all uncertain. It has been ascribed to entrapment neuropathy (Baxter and Thigpen 1984; Kenzora 1987), inflammation of the plantar fascia and periosteum (Furey 1975; Sewell et al 1980), calcaneal spur (DuVries 1957; Rosenfeld 1985) and stress fracture of the calcaneum (Graham 1983; Williams et al 1987). Some authors have suggested that the basic cause is within the heel pad, with a change in compressibility due to local loss of fat with thinning of the pad or to rupture of fibrous tissue septae (Miller and Lichtblau 1965; Snook and Chrisman 1972; Miller 1982).

The heel pad has a unique structure which is important for its shock-absorbing function. Dense strands of elastic fibrous tissue form circular or cone-shaped septae which enclose closely-packed fat cells. Jørgensen

S. Prichasuk, BSc, MD, MCh Orth, Associate Professor

Department of Orthopaedics and Rehabilitation Medicine, Faculty of Medicine, Mahidol University, Ramathibodi Hospital, Rama VI Road, Bangkok 10400, Thailand.

(C)1994 British Editorial Society of Bone and Joint Surgery

$0301-620 \mathrm{X} / 94 / 1693 \$ 2.00$
(1985) described a method of assessing the shockabsorbing function by measuring compression on lateral radiographs, loaded and unloaded by body-weight, but did not report any normal values. Amis et al (1988) found a significant increase in the thickness of the heel pad in the affected foot of 170 patients with unilateral heel pain, but did not study the elastic properties.

This study aimed to determine both the heel-pad thickness and its compressibility in patients with plantar heel pain and normal subjects, and relate them to age, sex and body-weight.

\section{PATIENTS AND METHODS}

From 1990 to 1992, 70 patients with plantar heel pain in 79 feet were seen in the orthopaedic clinic at Ramathibodi Hospital. All had had pain and localised tenderness beneath the heel for at least six weeks. Those with a history or any evidence of inflammatory joint disease, or local trauma and infection were excluded. There were eight men and 62 women; their mean age was 47.2 years (22 to 78), and there were 27 right feet, 34 left feet and nine patients with bilateral symptoms. A control group of 200 normal subjects was selected from patients' relatives, hospital personnel and medical students, stratified by age and sex into four groups: 50 men aged 20 to 35,50 men aged 40 to 60,50 women aged 20 to 35 , and 50 women aged 40 to 60 years. The five-year age gap was intentional, to make clear any difference between age groups.

Lateral radiographs were made of the feet, unloaded and loaded by body-weight, with a tube-film distance of 40 inches $(102 \mathrm{~cm})$, using $45 \mathrm{kV}$ and 5 mas $(125 \mathrm{~mA}$, $0.04 \mathrm{sec})$. The thickness of the soft-tissue shadow beneath the calcaneum was measured along a perpendicular line from the lowest part of the plantar tuberosity to the skin edge (Fig. 1). The ratio of the thickness in loaded and unloaded positions was defined as the heel-pad compressibility index (HPCI). An index approaching one meant lack of elasticity of the heel pad. The average thickness and HPCI of both feet were calculated for each normal subject and for patients in whom both feet were affected. The body mass index (BMI) was calculated for each patient and subject by dividing weight $(\mathrm{kg})$ by the square of the height $(\mathrm{m})$. Those with a BMI of over 27 were considered to be overweight (Bray, Jordan and Sims 1976). 


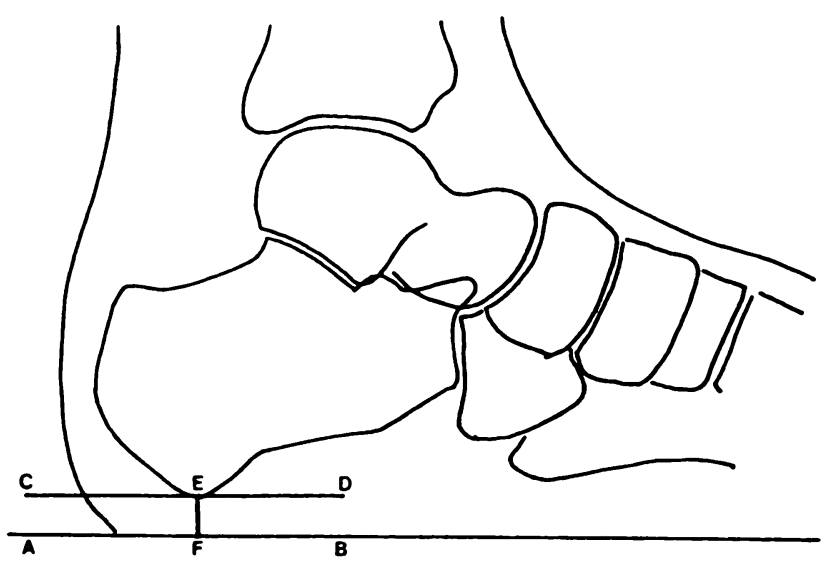

Fig. 1

Diagram of lateral radiograph of a loaded foot to show the measurement of heel-pad thickness (EF), between the skin line (AB), and the line of the plantar tuberosity of the calcaneum (CD).

A two-sample $t$-test was used to assess the differences in heel-pad thickness between groups, and the relation between BMI and HPCI was also determined.

\section{RESULTS}

The results for each group are shown in Tables I and II. Heel-pad thickness, HPCI and BMI were all significantly greater in patients with plantar heel pain than in normal subjects $(p<0.001)$. The BMI results showed that 28 of the 70 patients with plantar heel pain $(40 \%)$, but only
27 of 200 normal subjects $(13.5 \%)$ were overweight. Heel-pad thickness and HPCI were significantly higher in the overweight but otherwise normal subjects than in those of normal weight $(p<0.001)$.

In the control group, male heel-pad thickness was greater than female $(p<0.001)$, but there were no statistically significant sex differences for the HPCI and BMI $(p>0.05)$. As regards age, both heel thickness and HPCI were significantly higher in the normal subjects over $40(p<0.001)$.

\section{DISCUSSION}

Plantar heel pain is relatively common, but the precise aetiology is unknown. Perry (1983) suggested that repetitive trauma from walking and running can cumulate and lead to local inflammation and oedema, while Furey (1975) proposed a non-specific inflammatory process. There are few reports about changes in the heel-pad properties in normal and plantar heel-pain patients. The mean thickness of normal heel pads was reported to be have a mean of $17.8 \mathrm{~mm}$ by Steinbach and Russell (1964) and $18.62 \mathrm{~mm}$ by Gooding et al (1986), but neither found a correlation with age or sex. Many believe that the heel pad becomes thinner and softer in old age, and Kuhns (1949) demonstrated bony changes about the calcaneal tuberosity after the age of 40 years, taking them as evidence of loss of heel-pad elasticity.

We found that unloaded heel-pad thickness ranged from 14 to $27 \mathrm{~mm}$ (mean 18.77) which agrees with

Table I. Results in patients with plantar heel pain and normal subjects (mean \pm SD)

\begin{tabular}{|c|c|c|c|c|}
\hline & $\begin{array}{l}\text { Patients with } \\
\text { heel pain }\end{array}$ & $\begin{array}{l}\text { Normal } \\
\text { subjects }\end{array}$ & t-test & $\begin{array}{l}\text { p value of } \\
\text { difference }\end{array}$ \\
\hline Age & $47.17 \pm 9.68$ & $36.27 \pm 11.17$ & & \\
\hline Body-weight (kg) & $62.59 \pm 8.77$ & $58.31 \pm 10.99$ & & \\
\hline Height (cm) & $154.45 \pm 5.23$ & $160.32 \pm 9.38$ & & \\
\hline Body mass inde $x^{*}$ & $26.24 \pm .3 .42$ & $22.65 \pm 3.58$ & 7.31 & $<0.001$ \\
\hline Unloaded heel-pad thickness ( $\mathrm{mm}$ ) & $20.66 \pm 2.59$ & $18.77 \pm 2.33$ & 5.69 & $<0.0001$ \\
\hline Loaded heel-pad thickness (mm) & $12.13 \pm 2.64$ & $9.85 \pm 2.22$ & 7.02 & $<0.001$ \\
\hline Heel-pad compressibility index ${ }^{*}$ & $0.59 \pm 0.10$ & $0.52 \pm 0.08$ & 5.35 & $<0.001$ \\
\hline
\end{tabular}

* see text

Table II. Mean values of normal subjects grouped by sex and age

\begin{tabular}{|c|c|c|c|c|c|c|c|c|}
\hline \multirow[b]{2}{*}{ Value* } & \multicolumn{2}{|l|}{ Sex } & \multirow[b]{2}{*}{ t-test } & \multirow[b]{2}{*}{ p value } & \multicolumn{2}{|l|}{ Age (yr) } & \multirow[b]{2}{*}{ t-test } & \multirow[b]{2}{*}{ p value } \\
\hline & Male & Female & & & 20 to 35 & 40 to 60 & & \\
\hline UHPT & $19.42 \pm 2.45$ & $18.12 \pm 2.01$ & 4.11 & $<0.001$ & $18.27 \pm 2.25$ & $19.27 \pm 2.32$ & 3.11 & $<0.001$ \\
\hline LHPT & $10.26 \pm 2.25$ & $9.44 \pm 2.13$ & 2.66 & $<0.005$ & $9.08 \pm 2.10$ & $10.62 \pm 2.11$ & 5.19 & $<0.001$ \\
\hline HPCI & $0.53 \pm 0.08$ & $0.52 \pm 0.08$ & 0.82 & $>0.05$ & $0.49 \pm 0.08$ & $0.55 \pm(0.07$ & 5.24 & $<0.00) 1$ \\
\hline BMI & $22.84 \pm 3.31$ & $22.45 \pm 3.83$ & 0.77 & $>0.05$ & $21.22 \pm 2.90$ & $24.07 \pm 3.63$ & 6.15 & $<(0.00) 1$ \\
\hline
\end{tabular}

* UHPT, unloaded heel-pad thickness (mm); LHPT, loaded heel-pad thickness (mm); HPCI, heel-pad compressibility index: BMI, body mass index 
previous reports. Heel-pad thickness in males was greater than in females, and also in normal subjects after the age of 40 years. There is a tendency for body-weight to increase with age, and this could explain the increase after the age of 40 years. In the reported series, most patients were middle-aged women who showed greater heel-pad thickness and BMI than the normal control group. Amis et al (1988) have reported a significant increase in thickness of the heel pad in patients with plantar heel pain, and several other studies have shown a relationship between heel pain and increased body-weight (Snook and Chrisman 1972; Furey 1975; Hill and Cutting 1989). There have been few studies of heel-pad elasticity (Miller and Lichtblau 1965; Miller 1982; Jørgensen 1985), but we found that the HPCI is significantly increased in patients with pain, normal subjects over 40 years and

\section{REFERENCES}

Amis J, Jennings L, Graham D, Graham CE. Painful heel syndrome: radiographic and treatment assessment. Foot Ankle 1988; 9:91-9.

Baxter DE, Thigpen CM. Heel pain: operative results. Foot Ankle 1984; 5:16-25.

Bray GA, Jordan HA, Sims EA. Evaluation of the obese patient. 1. An algorithm. JAMA 1976; 235:1487-91.

DuVries HI. Heel spur (calcaneal spur). AMA Archives of Surgery 1957; $74: 536-42$

Furey JG. Plantar fasciitis: the painful heel syndrome. J Bone Joint Surg [Am] 1975; 57-A:672-3.

Gooding GA, Stess RM, Graf PM, et al. Sonography of the sole of the foot: evidence for loss of foot pad thickness in diabetes and its relationship to ulceration of the foot. Invest Radiol 1986; 21:45-8.

Graham CE. Painful heel syndrome: rationale of diagnosis and treatment. Foot Ankle 1983; 3:261-7.

Hill JJ, Cutting PJ. Heel pain and body weight. Foot Ankle 1989; 9:2546.

Jørgensen U. Achillodynia and loss of heel pad shock absorbency. Am J Sports Med 1985; 13:128-32. those who are overweight. Thus the elasticity of the heel pad is less in patients with heel pain, and decreases with increasing age and body-weight. More fat in a closed space, combined with a loss of elasticity of septae, may increase pressure.

Perry (1983) calculated that the impact load over the calcaneal tuberosity was about $5 \mathrm{~kg} / \mathrm{cm}^{2}$ with a repetition rate for walking of 1160 impacts per mile ( 721 per $\mathrm{km})$. Such repetitive trauma on a less elastic heel pad could lead to inflammation and oedema. It seems possible that the increase in heel-pad thickness with age and increasing body-weight leads to loss of the heel-pad elasticity and to liability to develop plantar heel pain.

No benefits in any form have been received or will be received from a commercial party related directly or indirectly to the subject of this article.
Kenzora JE. The painful heel syndrome: an entrapment neuropathy. Bull Hosp Jt Dis Orthop Inst 1987; 47:178-89.

Kuhns JG. Changes in elastic adipose tissue. J Bone Joint Surg [Am] 1949; 31-A:541-7.

Miller WE. The heel pad. Am J Sports Med 1982; 10:19-21.

Miller WE, Lichtblau PO. The smashed heel. Southern Medical J 1965; 58:1229-37.

Perry J. Anatomy and biomechanics of the hindfoot. Clin Orthop 1983; 177:9-15.

Rosenfeld S. Management of the heel spur (syndrome). J Am Podiatr Med Assoc 1985; 75:315-6.

Sewell JR, Black CM, Chapman AH, et al. Quantitative scintigraphy in diagnosis and management of plantar fasciitis (calcaneal periostitis): concise communications. J Nucl Med 1980; 21:633-6.

Snook GA, Chrisman OD. The management of subcalcaneal pain. Clin Orthop 1972; 82:163-8.

Steinbach HL, Russell W. Measurement of the heel pad as an aid to diagnosis of acromegaly. Radiology 1964; 82:418-22.

Williams PL, Smibert JG, Cox R, Mitchell R, Klenerman L. Imaging study of the painful heel syndrome. Foot Ankle 1987; 7:345-9. 